\title{
O PROCESSO DE ELABORAÇÃO DA LEI N. 11.738/2008 (LEI DO PISO SALARIAL PROFISSIONAL NACIONAL PARA CARREIRA E REMUNERAÇÃO DOCENTE): TRAJETÓRIA, DISPUTAS E TENSÕES*
}

\author{
Maria Dilnéia Espíndola Fernandes \\ Universidade Federal de Mato Grosso do Sul/UFMS \\ mdilneia@uol.com.br \\ Margarita Victoria Rodriguez \\ Universidade Federal de Mato Grosso do Sul/UFMS \\ poroyan@uol.com.br \\ Agência Financiadora: CNPq/CAPES/MEC/INEP
}

RESUMO:

O trabalho tem como objetivo resgatar a trajetória recente da construção da Lei do Piso Salarial Profissional Nacional (PSPN), para a carreira e remuneração docente no Brasil, no contexto da reforma do estado brasileiro, à medida que as alterações no papel do Estado redefiniram também as relações entre sociedade e governo. Assim, utilizaram-se a legislação federal pertinente, documentos produzidos em âmbito federal e sindical, e a literatura sobre a temática. Pontuam-se, como um dos embates importantes na construção dessa trajetória, as relações federativas brasileiras, marcadas, nesse momento histórico, por uma Ação Direta de Inconstitucionalidade (ADIn) contra a Lei n. 11.738/2008, impetrada por governadores de unidades subnacionais, questionando a jornada de trabalho e o salário instituído pela lei. Constatou-se que o PSPN está implantado em termos de concepção. A sua viabilidade material vai depender, ainda, de muito esforço por parte dos docentes da educação básica, bem como de possíveis equacionamentos nas relações políticas em torno do modelo federativo vigente no país.

Palavras-chave: Estado, política educacional, piso salarial profissional nacional

\section{LAW N. 11.738/2008 (NATIONAL PROFESSIONAL BASE SALARY FOR TEACHERS' CAREER AND PAY) MAKING PROCESS: TRAJECTORY, DISPUTES AND TENSIONS}

\begin{abstract}
:
The aim of the paper is to revisit the recent trajectory of a law-making process, namely the National Professional Base Salary Law (Piso Salarial Profissional Nacional, PSPN) for teachers' career and pay in Brazil, within the context of the Brazilian state reform, as the changes in the role of the State also redefined the relations between society and government. The study used the federal legislation, documents produced by the federal government and by the union, and the related literature. One important confrontation in the trajectory of that historical moment was an Unconstitutionality Direct Action against the Law n. 11.738/2008, filed by governors of sub-national units, questioning the working hours and the salary instituted by the law. The study evidenced that the PSPN is implemented, in terms of conception. Its material feasibility will depend both on the efforts made by basic education teachers, as well as on possible positioning on the political relationships regarding the country's current federative model.
\end{abstract}

Keywords: State, educational policy, national professional base salary 


\section{Introdução}

Este trabalho visa a analisar o processo de elaboração da Lei n. 11.738/2008, que instituiu o Piso Salarial Profissional Nacional (PSPN), com vistas à regulamentação da carreira e da remuneração dos profissionais da educação básica no Brasil.

Para tanto, utilizaram-se fontes primárias, tais como: a legislação federal, documentos produzidos no âmbito dos poderes legislativo, executivo, judiciário e do movimento sindical, com o intuito de desvelar a trajetória, as disputas e as tensões que vêm circundando o processo de implementação da Lei.

Considera-se que a promulgação da Lei n. 11.738/2008 representa um momento histórico de condensação das lutas em torno de melhores condições de trabalho e de remuneração dos trabalhadores em educação do país. Com efeito, trata-se de um processo que remonta ao século XIX e que só se efetivou na primeira década do século XXI, porque só então as condições objetivas e subjetivas se fizeram concretas.

Apesar disso, foi com a elaboração e a promulgação da Constituição Federal de 1988 que as demandas pela valorização do magistério se materializaram em perspectivas jurídico-legais, dado o contexto econômico, social e político que permeou tal processo e que propiciou condições materiais e ideológicas para a redefinição das relações entre sociedade e Estado.

Essa redefinição, pela concepção constitucional que se inaugurava, marcou a possibilidade de se construir, a partir de então, o chamado Estado de direito democrático social. Recolocou, inclusive, para a sociedade brasileira, eleições diretas para o chefe do executivo nacional, após 21 anos de ditadura civil militar no país, período que foi marcado pela 'limitação' dos direitos políticos e o cerceamento dos direitos sociais.

Ocorreu que o projeto de nação vencedor naquele momento histórico alocava a crise do capital no âmbito do Estado. Diante disso, o Estado, que havia até então sido chamado a resolver a crise cíclica do capital que se aprofundou em 1929, agora era convidado a retirar sua intervenção da economia. Pontua-se que justamente a intervenção do Estado na economia foi o que passou a ser alvo das críticas do pensamento neoconservador.

Apesar da crítica, o Estado continuou a intervir intensa e radicalmente tanto na economia quanto na organização do mundo do trabalho, com o intuito de garantir as condições de transferência dos excedentes econômicos gerados pelas camadas sociais cada vez mais empobrecidas para os grupos econômicos dominantes.

Durante os anos de 1980 e 1990, portanto, foram implementadas diversas medidas com o objetivo de reconfigurar o papel do Estado para atender aos interesses econômicos dos grupos hegemônicos e, assim, assegurar a livre circulação dos bens e capitais nacionais e estrangeiros. Podem-se destacar, entre essas medidas, as políticas de desregulação do mercado, privatizações de empresas públicas, flexibilização das relações de trabalho, políticas de estabilização de preços e ajustes fiscais.

A instabilidade política, produto da crise econômica e social instalada no Brasil durante os anos de 1980, não foi superada durante o período democrático, iniciado com a eleição de Tancredo Neves. Muito pelo contrário: quando José Sarney assumiu o governo após a morte de Tancredo, teve que executar planos econômicos cujo objetivo era deter a inflação e controlar a crise econômica.

A situação de instabilidade manteve-se durante a gestão do presidente Fernando Collor de Mello, quando a alta inflação e o desemprego permaneceram constantes. Também continuaram as práticas políticas oligárquicas e fisiológicas; a promessa de campanha da moralidade pública de combate à corrupção jamais foi cumprida. Tal situação 
gerou o repúdio de vários segmentos da sociedade brasileira, especialmente dos jovens, dos aposentados e dos trabalhadores. A gestão administrativa desastrosa, as denúncias de corrupção e o fracasso da política de 'modernização' da economia que afetaram vários segmentos da indústria brasileira descredibilizaram totalmente o governo de Collor (ANTUNES, 1999).

O processo de impeachment sofrido pelo 'Caçador de Marajás' levou o Estado brasileiro a ter um novo chefe do executivo nacional que, mesmo sendo representante das tradicionais elites políticas, devido às pressões sociais, foi obrigado a desobedecer a um preceito caro ao neoliberalismo, que é o de não reconhecer as corporações porque, dizem os neoliberais, as corporações são nocivas à democracia porque defendem privilégios.

$\mathrm{Na}$ verdade, os neoliberais retomam a crítica do liberalismo clássico a respeito dos privilégios dos membros das corporações de ofícios constituídas pelos mestres. Segundo Adam Smith (1985), os privilégios interferem e impedem negativamente no livre exercício profissional porque impedem a passagem do trabalhador de um ofício para outro.

$\mathrm{O}$ autor entende que as associações controlariam a organização da produção artesanal e interfeririam no planejamento, produção e qualidade da mercadoria e que, além de regulamentar a comercialização, a intervenção seria uma barreira ao livre desenvolvimento da economia. Por tal motivo, o poder público deveria desestimular a sua organização.

Apesar da crítica e do combate dos liberais clássicos e neoliberais, essas organizações continuam a existir porque são inerentes à divisão do trabalho dentro do modo de produção capitalista.

Com efeito, a organização dos trabalhadores em associações e sindicatos tem como objetivo a união dos trabalhadores a fim de defender os direitos trabalhistas, bem como lutar por melhores condições de trabalho e salários. Considerar, portanto, essas agremiações como corporações é negar as condições materiais que lhes dão origem, ou seja, a divisão do trabalho, a expropriação do conhecimento dos trabalhadores e a maisvalia.

Desse modo, entre os supostos privilégios defendidos pela 'corporação dos professores brasileiros' organizados na Confederação Nacional dos Trabalhadores em Educação (CNTE) ${ }^{1}$, encontrava-se, ainda, a luta por realizar aquilo que foi garantido como concepção para os profissionais da educação pela Constituição Federal de 1988, ou seja, melhores garantias de condições materiais de existência.

Obviamente que tal preceito constitucional foi garantido com muita luta e resolução da 'corporação' representada pela CNTE. Afinal, Estado de direito democrático social não é um presente: é, antes, uma conquista daqueles que, em determinado momento histórico, conseguem se organizar para tal feito.

Diante disso,

A questão da valorização dos profissionais do ensino está prevista no artigo 206, inciso V, da Constituição Federal de 1988 (CF-88), o qual determina como principio educacional a garantia, na forma da lei, de planos de carreira para o magistério público e piso salarial profissional, além de ingresso exclusivamente por concurso público de provas e títulos, com importantes desdobramentos para a educação nacional (CAMARGO et al., 2009, p. 343).

Por isso mesmo, o Ministro da Educação do período, Murilo Hingel, recebeu a CNTE para tratar da questão da possibilidade da construção de um Piso Salarial Profissional Nacional (PSPN) para o magistério público. Como resultado dessas 
negociações, em 1994 foi assinado um Acordo Nacional com o Governo de Itamar Franco, que foi rompido em 1995, quando assumiu o governo Fernando Henrique Cardoso.

Pontua-se que o diálogo iniciado pela CNTE e o governo aconteceu num contexto econômico e político não muito propício. As negociações, ao que parece, não aconteceram a contento.

Já eram tempos de outras definições, como as que se originaram da Conferência Mundial de Educação para Todos, realizada em Jontiem, na Tailândia, em 1990. Em razão disso, gerou-se no Brasil o consenso para a construção do Plano Decenal de Educação a partir de 1993.

Tal consenso teve lugar já no âmbito da reforma do Estado, mais especificamente das reformas educacionais empreendidas durante os anos de 1990, que intensificaram a privatização da educação, bem como sua descentralização e municipalização e, ainda, introduziram a gestão empresarial na educação básica.

Ainda assim a 'corporação' continuou a desafiar o Estado em busca de materializar os ganhos conceituais do Estado democrático de direito social. O desafio consistiu em persistir na organização dos trabalhadores do setor educacional para a luta.

A continuidade do processo democrático brasileiro pela via eleitoral colocou em 1995, na chefia do executivo federal, o denominado, conforme Oliveira (1999, p. 81) "príncipe dos sociólogos": chegara a era Fernando Henrique Cardoso.

Foi a era do desmonte do estado via privatizações, por um lado, e desorganização da classe trabalhadora, por outro (OLIVEIRA, 1999).

Tal projeto foi passível de execução em razão mesmo da indução que a reestruturação produtiva, via novas tecnologias, operou na condução da mundialização do capital, que engendrou também a possibilidade histórica da reforma do Estado, na construção de um novo padrão de acúmulo do capital com vistas a restaurar o poder de classe (HARVEY, 2008). Diante disso, com a substituição extensiva do trabalho humano pelo trabalho da máquina, por um lado, e do desmonte ideológico das 'corporações' dos trabalhadores, por outro, as negociações entre governo e os profissionais da educação em torno da materialização das conquistas do Estado de direito democrático social cessaram.

No lugar, entrou uma nova pauta na agenda governamental, oriunda das recomendações das agências multilaterais de fomento, em consenso com as elites nacionais, que era a de financiar "em contexto de escassez de recursos, a política educacional, por meio de políticas de fundos" (CEPAL, UNESCO, 1995, p. 355). Tal recomendação pode ter sido uma das razões da promulgação da Lei n. 9.424/1996, que instituiu o Fundo de Manutenção e Desenvolvimento do Ensino Fundamental e de Valorização do Magistério (Fundef), que regulamentou a Medida Provisória n. 14/1996, quatro dias antes da promulgação da nova Lei de Diretrizes e Bases da Educação Nacional, Lei n. 9.394/1996.

\section{A reforma do estado brasileiro e suas novas relações com a sociedade}

A estratégia construída pelo executivo federal para a aprovação da Emenda Constitucional n. 14/1996 e da lei que a regulamentou (9.424/1996) mostrou como, a partir de então, o executivo federal sinalizou que relação estabeleceria com a sociedade e que, por isso mesmo, qualquer possibilidade de negociação com setores organizados da sociedade se daria agora em novos marcos.

A proposta de reforma do Estado empreendida durante a administração de Fernando Henrique Cardoso visou a criar novos consensos entre capital e trabalho. Assim, as negociações sindicais não tiveram mais sentido, porque a reestruturação capitalista 
sinalizou uma nova forma de lidar com o mundo do trabalho, a 'impositiva', uma vez que haviam se reduzido os postos de trabalho, situação que colocou os trabalhadores em empregabilidade precária.

A supremacia do poder executivo, nesse momento histórico, foi possível devido às condições construídas desde 1989, que vinham alinhavando as bases do governo neoliberal, por meio das privatizações das estatais, por um lado, e do endurecimento nas negociações com setores organizados da classe trabalhadora, por outro. Um exemplo disso, que ficou na história, foi como o governo FHC tratou a greve dos petroleiros em 1995: a toque de recolher, com tanques militares nas portas das refinarias.

Diante dessa conjuntura, o processo da perspectiva de construção de um PSPN para os profissionais da educação básica configurou-se no valor do custo/aluno/ano/mínimo instituído pela Lei n. 9.424/1996, (Fundef), a ser praticado a partir de 1998.

É verdade que o Fundef reservou no mínimo $60 \%$ da sua receita para salários de professores $^{2}$ e que também dispôs sobre a criação de Conselhos de Acompanhamento e Controle Social (CACS $)^{3}$. A folha de pagamento de muitos estados para os salários de profissionais da educação já mostrava, em 1998, que custavam mais que os $60 \%$ estabelecidos na lei (FERNANDES, 2003). Esse fato explica-se porque, historicamente no Brasil, as redes estaduais das regiões Sudeste, Sul e Centro-Oeste sempre se responsabilizaram mais pelas matrículas da educação básica.

Essa situação levou vários estados a gastarem até $100 \%$ dos seus recursos para manutenção e desenvolvimento do ensino (MDE), só com a folha de pagamento, porque muitos estados passaram a transferir recursos para o Fundo.

A lei do Fundo também dispôs que o recurso se destinaria aos salários para os professores efetivamente em exercício no magistério do ensino fundamental. Tal disposição levou as administrações educacionais em estados e municípios a resolver o constrangimento disciplinado pela lei. Por exemplo, os salários de professores da educação infantil e do ensino médio, que não eram incluídos no Fundef, mesmo assim foram pagos com os recursos do Fundo.

Ainda, o constructo dos CACSs apontou experiências das mais variadas possíveis no âmbito de estados e municípios. Desde os CACSs que se legitimaram como conselhos de acompanhamento e controle estatal, até os que alegavam não ter o menor domínio de conhecimento do que lhes era exigido em termos de fiscalização para a aplicação dos recursos em MDE (DAVIES, 1999).

A organização contábil do Fundef na distribuição e redistribuição dos impostos vinculados à educação $(15 \%$ dos $25 \%$ de impostos vinculados, conforme o artigo 212 da Constituição Federal de 1988) produziu diversas situações de entendimento de sua operacionalidade. Verificou-se que vários prefeitos, em muitos municípios do país, entenderam tratar-se de uma lei que os obrigava a pagar um salário mínimo para seus professores, algo em torno de $\mathrm{R} \$ 315,00$, à medida que este foi o valor do custo/aluno/ano/mínimo instituído no primeiro ano de vigência do fundo. Houve, também, situações de acirradas tensões entre o governo das unidades subnacionais com as prefeituras de seu estado, em virtude das disputas pelas matrículas do ensino fundamental (DAVIES, 1999).

Constatou-se, outrossim, que estados e municípios promoveram processos de inflacionamento de dados censitários de matrículas. E mais grave ainda: no processo de elaboração das constituições estaduais e das leis orgânicas municipais que se seguiram à promulgação da Constituição Federal de 1988, muitos entes federados que haviam vinculado recursos para a MDE em patamar superior aos dispostos pela Constituição 
Federal de 1988, com a instituição do Fundef, reduziram esses recursos, mediante emendas às constituições e leis orgânicas (PINTO, 2003).

Nesse contexto de redefinições do papel do Estado (PERONI, 2003), paulatinamente se substituíram as conquistas do Estado de direito democrático social a partir da intensificação de políticas de restrições e constrangimentos à classe trabalhadora. Em consequência disso, para os profissionais da educação básica, perdeu-se a possibilidade de construção de um PSPN, à medida que se implantou o valor do custo/aluno/ano/mínimo, materializado na reforma da política educacional para o financiamento da educação básica.

\section{Novas redefinições no âmbito do Estado hodierno}

O ajuste estrutural provocado pela onda neoliberalizante, que promoveu a retirada da intervenção do Estado na economia, por meio das privatizações e da focalização das políticas sociais, no início do século XXI, deu sinais de exaustão. $\mathrm{O}$ aprofundamento das desigualdades sociais fez com que "a direção do projeto neoliberal da Terceira Via" (NEVES, 2005, p. 115) decidisse agora que nem o mercado pode tudo, quanto o Estado também não pode.

No caso brasileiro, em 2002, assumiu o governo federal Luís Inácio Lula da Silva, do Partido dos Trabalhadores (PT), em uma ampla aliança política com a burguesia industrial. Embora em seu programa de governo apresentasse princípios e diretrizes alternativos ao ideário neoliberal, sua administração revelou as profundas contradições que engendram o modo de produção capitalista.

Nessa conjuntura, o movimento docente intensificou suas lutas com relação à defesa de melhores condições de trabalho e salários. Prova disso foi o número crescente de greves registradas nos diversos estados da federação durante os últimos anos da primeira década do século - por exemplo, os professores do estado de São Paulo fizeram greves em junho de 2000, 2007, 2008, 2009 e 2010. Em julho de 2008 deflagraram greve os professores do estado de Minas Gerais e da Bahia. De igual modo em 2009 se somaram os docentes do estado de Sergipe, Maranhão, Rio de Janeiro, Distrito Federal, Rio Grande do Norte, entre outros. Essa mobilização teve seu ponto mais agudo quando se declarou 24 de abril de 2007 como um dia de luta dos professores de todo o país, em defesa da implantação integral da Lei do PSPN, movimento que teve repercussão nacional.

As organizações sindicais, científicas e acadêmicas docentes tentaram intervir e participar do novo processo político instalado no Brasil, no período 2002/2009. Particularmente, participaram do debate sobre o Fundeb e estiveram presentes no Congresso Nacional na discussão do financiamento da educação básica e a implantação do PSPN.

A CNTE elaborou uma proposta de PSPN em 2006, que apresentou em 2007 ao Ministério da Educação (MEC); ao Conselho dos Secretários Estaduais de Educação (CONSED); ao Ministério do Trabalho e Emprego (MTE) e encaminhou ao Congresso Nacional um Projeto de Lei de PSPN. Pontua-se que o Poder Executivo também apresentou, no Congresso Nacional, um Projeto de Lei, em 02 de abril de 2007, que fixava um PSPN para o magistério, sem, contudo, ter dialogado com os trabalhadores em educação (CNTE, 2007).

Diante disso, a CNTE manifestou-se contra tal situação e convocou os trabalhadores em educação, bem como a sociedade brasileira, para, no dia 24 de abril de 2007, realizar um dia de Marcha e de Paralisação Nacional pela Educação, para repudiar essa iniciativa e pressionar o Congresso Nacional para a aprovação das emendas 
defendidas pela CNTE, luta que continuou durante todo o ano de 2008 e de 2009 e até depois de aprovada a Lei que instituiu o PSPN.

Nesse contexto, redesenharam-se novas relações a partir de novas estratégias de consenso, que se foi construindo com vistas a

[...] dar continuidade à execução de reformas estruturais, em especial aquelas que visam à desregulamentação das relações de trabalho (reformas da previdência, trabalhista e sindical) e aprofundar o modelo de radicalização democrática iniciado no segundo governo FHC. O governo Lula da Silva, pelo menos até seu segundo ano de mandato, vem mantendo a mesma política econômica monetarista de seu antecessor e, no plano político, vem tentando consolidar a formação do novo homem coletivo indispensável ao projeto de sociabilidade neoliberal da Terceira Via (NEVES, 2005, p. 95).

Foi nessa conjuntura de construção de novas sociabilidades que a reforma da política educacional ensejou novas reformas. Para o propósito deste trabalho, interessa a transformação do Fundef em Fundeb, que se operou por meio da aprovação da emenda à Constituição de n. 53/2006, quando "a questão da valorização profissional do magistério continuou central" (CAMARGO, et al., 2009, p. 344), ao menos em âmbito de concepção legal.

Decorreu desses novos artifícios jurídicos legais a concepção posta na lei 11.738/2008 (BRASIL, 2008a), que instituiu o

[...] valor do PSPN (que) foi fixado em $\mathrm{R} \$ 950,00$, sendo este fixado como o valor abaixo do qual os diferentes entes federados não poderiam estipular o vencimento inicial das carreiras do magistério público da educação básica com formação em nível médio na modalidade normal (art. 62 da LDB), com carga semanal de 40 horas de trabalho, podendo compreender as vantagens pecuniárias já existentes. A partir de 2009, tal piso deverá ser atualizado anualmente no mesmo percentual estabelecido pelo Fundeb para o valor aluno ano das séries iniciais do ensino fundamental, a ser reajustado de acordo com o INPC/IBGE (CAMARGO et al., 2009, p. 345).

Assim, a CNTE anunciou que, de acordo com a Portaria Ministerial n. 211, publicada no Diário Oficial da União em 10 de março de 2009, que estabeleceu o valor anual mínimo nacional por aluno do Fundeb, esse valor deveria ser reajustado em $2010 \mathrm{em}$ $19,2 \%$, cujo percentual também passaria a valer para reajustar o PSPN.

Diante disso, a CNTE reforçou o "elo entre o Fundeb e o PSPN do magistério" porque

De Acordo com o art. 5 da lei n. 11.738, de 16 de julho de 2008, que instituiu o piso salarial nacional do magistério da educação básica, a correção do piso deve pautar-se pelo mesmo percentual de reajuste do valor mínimo nacional do Fundeb. Assim, o valor de $\mathrm{R} \$ 950,00$, definido para 2008, passa a ser de $\mathrm{R} \$ 1.132,40 \mathrm{em} 2009$. É preciso destacar que o projeto de lei n. 3.776/08, que visa instituir o INPC/IBGE como índice de reajuste do piso, ainda não foi concluído na Câmara e também deverá tramitar no Senado. (disponível em: $<$ http://www.cnte.org.br/index.php?option=com_content\&task=view\&id $=1932 \&$ Itemid $=87>$. Acesso em: 27 out. 2009) 
A CNTE lembrou, nessa mesma edição, que:

\begin{abstract}
Ocorre, no entanto, que muitos gestores, com base no julgamento da liminar da Ação Direta de Inconstitucionalidade contra a lei do piso, movida pelos governadores do RS, SC, PR, MS e CE (com o apoio de José Serra/SP, Aécio Neves/MG, José Roberto Arruda/DF, Marcelo Miranda/TO e José de Anchieta Jr/RR), tendem a desconsiderar o reajuste de $19,2 \%$, sob a alegação de que a decisão do STF teria alcançado este dispositivo da lei. Para a CNTE, no entanto, este ponto encontra-se inabalável, devendo, sim, o reajuste ser aplicado retroativamente a janeiro.

Além da controvérsia sobre o reajuste do piso, em 2009, os poderes executivos, com base na omissão do STF em publicar o acórdão sobre a decisão da liminar à ADI 4167, questionam, ainda, a forma de integralização do valor do piso - se $\mathrm{R} \$ 950,00$ como remuneração bruta em 2009, uma vez que o conceito de vencimento a que se amparava a integralização do piso foi desconsiderado pelo Tribunal, até julgamento do mérito da ação; ou se na forma progressiva, acrescendo à remuneração e o valor do piso em 2009. (disponível em: $<$ http://www.cnte.org.br/index.php?option=com_content\&task=view\&id $=1932 \&$ Itemid $=87>$. Acesso em: 27 out. 2009)
\end{abstract}

Ainda de acordo com dados da CNTE, em 2009, "em vários estados, incluindo alguns do Sul e Sudeste, professores de nível médio percebem vencimentos em início de carreira (computados para aposentadoria) abaixo do Salário Mínimo" (CNTE, 2009).

Apesar da luta e mobilização dos docentes, a maioria dos estados e municípios, no final do ano de 2009, não cumpria a Lei n. 11.738/2008, que instituiu o PSPN do magistério da educação básica, uma reivindicação histórica do movimento sindical dos trabalhadores em educação.

Os governadores dos estados e os prefeitos que não ajustaram os salários dos docentes alegaram falta de recursos. Com efeito, de acordo com a CNTE, entre $60 \%$ e $65 \%$ dos docentes do país recebem menos que $\mathrm{R} \$ 950,00$ e se registram salários em alguns estados menores que o salário mínimo, como no Ceará, onde um docente com titulação de ensino médio por 20 horas de trabalho tem um salário de $\mathrm{R} \$ 218,00$ e de $\mathrm{R} \$ 437,88$ por 40 horas e o docente com licenciatura plena recebe $\mathrm{R} \$ 392,91$ por 20 horas e 785,84 por 40 horas; os docentes do estado de Pernambuco com titulação de nível médio recebem $\mathrm{R} \$$ 435,00 por 30 horas e $\mathrm{R} \$ 593,76$ por 40 horas, e os docentes com licenciatura plena recebem RS 467,00 por 30 horas e $\mathrm{R} \$ 635,00$ por 40 horas.

$\mathrm{O}$ desrespeito à legislação nacional condiciona a materialização de uma política salarial nacional que oferece as garantias mínimas para a estabilidade e a valorização do trabalho docente. De fato, a disparidade salarial entre os estados é mais uma das manifestações das desigualdades regionais e sociais do Brasil.

Ainda, de acordo com dados da CNTE, em 2009 alguns estados pagavam aos docentes com carga horária de 40 horas e diploma de licenciatura plena salários iniciais que superavam o PSPN, como o caso de Alagoas ( $\mathrm{R} \$ 2.030,00)$, Distrito Federal ( $\mathrm{R} \$$ $1.760,00)$ e Tocantins ( $\mathrm{R} \$ 2.020,00)$. Entretanto, estados como Minas Gerais ( $\mathrm{R} \$ 850,00)$ ou Santa Catarina (R $\$ 830,25)$ não alcançavam o previsto pelo piso salarial (JORNAL DO SENADO, 9/3/2009). 
Enfim, a proposta do PSPN para todos os docentes do país é um projeto que remonta ao período Imperial e teve sua origem na Portaria de 3 de abril de 1822, do estado de Ceará, que elevou o salário dos professores a 150\$000 anuais e visava à valorização do magistério, porque era uma categoria considerada de suma importância para promover o conhecimento. No entanto, dada a falta de recursos, o aumento foi suspenso.

Posteriormente, o Imperador, com a finalidade de assegurar recursos para a remuneração dos docentes, sancionou dois decretos no dia 26 de julho de 1827, um que fixava o salário mínimo de $150 \$ 000$ anuais para os professores de primeiras letras e outro que estipulava "[...] suprir com as rendas geraes o que faltar no subsidio literario para pagamento dos Professores de primeiras letras e grammatica latina".

E em 15 de outubro de 1827, foram promulgadas a Lei do Piso Salarial e a Lei Geral da Educação. Apenas esta última vigorou, porém com restrições a respeito da questão dos salários dos profissionais da educação.

A lei que criou o PSPN e que foi assinada pelo Marquês de Queluz determinava, no artigo $3^{\circ}$, um salário mínimo de $200 \$ 000$ a $500 \$ 000$ anuais, “[...] com atenção às circunstâncias da população e carestia dos lugares" para os professores de primeiras letras e de gramática latina. Além disso, os artigos $7^{\circ}$ e $9^{\circ}$ regulamentavam que o ingresso à carreira docente era mediante concurso público.

Essa lei não foi implantada devido à falta de recursos financeiros, embora o poder Legislativo houvesse previsto recursos complementares, mediante rendas gerais do Império, destinadas às províncias para arcar com a receita do subsídio literário, que era um tributo destinado ao financiamento da educação (MONLEVADE, 2000).

Os professores brasileiros, historicamente, lutaram pela aprovação do piso salarial com os objetivos de valorizar o trabalho docente, combater as desigualdades regionais tanto quanto as salariais, e defender o pagamento de salários que respeitem a dignidade dos trabalhadores da educação, a melhoria da oferta e da qualidade de ensino.

Mas o fato de ser aprovada a Lei n. 11.738/2008 não significou o fim da luta. Um dos desafios com o qual o magistério tem que conviver é o modelo federativo adotado pelo país. O federalismo brasileiro sustenta-se na autonomia dos entes federados, por um lado, e na interdependência entre eles, por outro (ABRÚCIO, 2006).

Foi em nome da autonomia das unidades subnacionais que os governadores dos estados do Rio Grande do Sul, Santa Catarina, Paraná, Mato Grosso do Sul e Ceará - que contaram com o apoio dos governadores dos estados de São Paulo, Minas Gerais, Tocantins e do Distrito Federal - resolveram questionar a legitimidade do governo central em relação à Lei do PSPN.

Esses governadores, em 28 de outubro de 2008, entraram na Justiça com uma Ação Direta de Inconstitucionalidade (ADIn), de n. 4.167, e depois de uma série de exposições de motivos de ordem orçamentária e administrativa, formularam o seguinte requerimento:

Em suma, demonstrou-se que os artigos impugnados $\left(\S 1^{0} \mathrm{e} 4^{0}\right.$, do art. $2^{0} \mathrm{e}$ art. $3^{0}$, II e III, e $8^{0}$ da Lei 11.738 , de 16 de julho de 2008) são flagrantemente inconstitucionais e operam contra a autonomia e desenvolvimento dos sistemas de ensino de Estados, Distrito Federal e Municípios, além de implicar violação a normas constitucionais que disciplinam a política orçamentária.

Ex positis, requer-se seja concedida a cautelar para suspender, ex tunc, a aplicabilidade dos dispositivos legais objeto da ação até seu julgamento definitivo. 
Ao final, requer seja a presente ação julgada procedente para declarar a inconstitucionalidade dos $\$ 1^{0}$ e $4^{0}$, do art. $2^{0}$ e art. $3^{0}$, II e III, e $8^{0}$ da Lei 11.738, de 16 de julho de 2008 (BRASIL, 2008a).

Essa ação gerou um debate no interior do Poder Judiciário a respeito da constitucionalidade da Lei. O que estava em discussão, porém, era a composição da jornada de trabalho e a questão do vencimento, previstos na Lei no Artigo $2^{\circ}$, que sofreu alterações:

$\S 1^{\circ}$ que estabelece "O piso salarial profissional nacional é o valor abaixo do qual a União, os Estados, o Distrito Federal e os Municípios não poderão fixar o vencimento inicial das Carreiras do magistério público da educação básica, para a jornada de, no máximo, 40 (quarenta) horas semanais".

$\S 4^{\circ} \mathrm{Na}$ composição da jornada de trabalho, observar-se-á o limite máximo de $2 / 3$ (dois terços) da carga horária para o desempenho das atividades de interação com os educandos (BRASIL, 2008b).

O Relator do processo foi o ministro Joaquim Barbosa. Seu parecer recomendou o indeferimento total dos pedidos cautelares, porque entendeu que os argumentos dos governadores eram improcedentes, dado que não tinham provas fáticas dos possíveis prejuízos financeiros. Embora houvesse certa divergência com relação à interpretação da lei entre os nove ministros do Supremo Tribunal Federal (STF) que participaram da votação, o STF adotou uma posição contrária à do relator do processo.

Os ministros consideraram que, até o julgamento final da ADIn n. 4.167, o termo 'piso' deve ser entendido como a remuneração mínima que os docentes devem receber, ou seja, não poderão ganhar um valor menor que $\mathrm{R} \$ 950,00$ somados o vencimento básico salário - e as gratificações e vantagens.

Também por maioria, os ministros decidiram retirar o parágrafo $4^{\circ}$ do artigo $2^{\circ}$, que estipulava o cumprimento de, no máximo, 2/3 da carga de trabalho dos professores para o desempenho de atividades em sala de aula, mas mantiveram o parágrafo $1^{\circ}$, que fixava a jornada de 40 horas semanais de trabalho, até o julgamento final da ação. A seguir, transcreve-se a decisão do Tribunal Pleno do dia 17/12/2008, que deferiu em parte a liminar:

Decisão: O Tribunal deferiu parcialmente a cautelar para fixar
interpretação conforme ao artigo $2^{\circ}$, da Lei ${ }^{\circ} 11.738 / 2008$, no sentido de
que, até o julgamento final da ação, a referência do piso salarial é a
remuneração; deferiu a cautelar em relação ao $\S 4^{\circ}$ do artigo $2^{\circ}$; e deu
interpretação conforme ao artigo $3^{\circ}$ para estabelecer que o cálculo das
obrigações relativas ao piso salarial se dará a partir de 01 de janeiro de
2009 , vencidos parcialmente o Senhor Ministro Ricardo Lewandowski,
que também deferia a cautelar quanto ao inciso II do artigo $3^{\circ}$, e o Senhor
Ministro Marco Aurélio, que deferia integralmente o pedido de cautelar
(BRASIL, 2008c).

Como se pode observar, o cenário político e jurídico evidencia que os docentes terão que transitar um longo caminho para que se instaure no Brasil uma verdadeira política de valorização da atividade docente. Os ministros do STF, ainda com uma visão conservadora, defendem os interesses dos grupos dominantes e se manifestam contrariamente às definições a respeito dos salários da categoria docente que foram 
construídas historicamente pelos trabalhadores da educação e consolidadas no âmbito do Congresso Nacional.

\section{Considerações Finais}

O trabalho demonstra que na segunda metade dos anos de 1980, durante o processo de redemocratização da sociedade brasileira, foi possível, devido a um intenso e complexo processo de correlação de forças sociais, vislumbrar a perspectiva da construção de um Estado de direito democrático social, inscrito no texto constitucional que, para o mundo do trabalho, expressou conquistas significativas com vistas à sua reprodução.

Tal perspectiva retraiu-se a partir mesmo de 1990, quando a "classe dominante e dirigente, sob a direção do quem vem se denominando de liberal-socialismo ou socialismoliberal" (NEVES, 2005, p. 38) encetou a reforma do estado brasileiro na condução neoliberal. Foi assim que a reforma do Estado pelo neoliberalismo provocou

Uma libertação da máquina do Estado do universo alargadamente volúvel, incerto e destemperado da democracia representativa. A Nova Direita, [...] como os da chamada escola Public Choice, retoma a ofensiva 'desemancipadora' dos velhos liberais do século XIX, na sua luta contra a entrada das massas na vida política, por intermédio dos sindicatos, dos partidos ou do sufrágio (MORAES, 2002, p. 19).

Foi nesse contexto que a possibilidade mais recente de se estabelecer um PSPN para os docentes da educação básica, no governo de Fernando Henrique Cardoso, pareceu ter migrado para a construção do valor do custo/aluno/ano/mínimo, materializando-se nas políticas de fundos para financiar a manutenção e o desenvolvimento do ensino (Fundef), muito embora o texto constitucional tivesse garantido, como direito, muitas das reivindicações oriundas das lutas dos trabalhadores por melhores condições de trabalho e salário. A Lei n. 11.494/2007, que instituiu o Fundeb, manteve a mesma lógica contábil e operacional do Fundef. Houve, aqui, um aclamado debate para que o Fundeb estendesse de $60 \%$ para $80 \%$ os recursos dispostos para salário dos docentes da educação básica. Prevaleceram, contudo, os 60\% para despesas com MDE para aplicar em salários nas esferas estadual e municipal.

Em 2008, a Lei n. 11.738 instituiu de direito o PSPN. Contudo, de fato, sua inviabilização persiste no horizonte das intrincadas relações federativas historicamente construídas no país.

Por isso mesmo cinco governadores estaduais resolveram questionar o modelo federativo que tende a se sustentar na "especificidade do Estado federal, [que] é o compartilhamento da soberania entre o governo central [...] e os governos subnacionais" (ABRUCIO, 2006. p. 92), para fazer valer "o princípio da soberania compartilhada [que] deve garantir a autonomia dos governos e a interdependência entre eles" (Idem, ibid., p. 92).

Parece que a interpretação de modelo federativo por parte dos governadores em questão - particularmente para a implantação do PSPN - indica muito mais um tensionamento político com a esfera federal, mostrando o quão forte ainda é o regional no contexto político do país, do que de fato esses governadores estariam dispostos a promover um saudável exercício de equacionamento das finanças públicas em prol da construção de um pacto federativo compensatório e equilibrador das desigualdades regionais que se expressam por todo o cenário nacional. 
Cabe ressaltar que, no dia 10 de março de 2010, os professores de todo o país organizaram o Dia de Mobilização de Estados e Municípios, com vistas à preparação da Paralisação Nacional em defesa da implantação do PSPN, que ocorreu no dia 16 de março do mesmo ano. Essa situação evidencia que, embora a Lei em âmbito federal esteja promulgada, ainda não foi implantada em muitas unidades subnacionais.

\section{Referências:}

ABRUCIO, F. L. Para além da descentralização: os desafios da coordenação federativa no Brasil. In: FLEURY, S. (Org.). Democracia, descentralização e desenvolvimento: Brasil \& Espanha. Rio de Janeiro: Editora FGV, 2006.

ANTUNES, R. Os sentidos do trabalho - ensaio sobre a afirmação e a negação do trabalho. São Paulo: Boitempo, 1999.

BRASIL. (Constituição). Constituição Federal de 1988. Diário Oficial da República Federativa do Brasil. Brasília, DF, 05 out. 1988.

LDB \& Lei do Fundef. Câmara dos Deputados. Comissão de Educação, Cultura e Desporto. Coordenação de Publicações. Brasília, 2001.

. Emenda Constitucional n. 53, de 19 de dezembro de 2006. Dá nova redação aos arts. $7^{\circ}, 23,30,206,208,211$ e 212 da Constituição Federal e ao art. 60 do Ato das Disposições Constitucionais Transitórias. Disponível em:

<http:www.planalto.gov.br/ccivil_03/constituição/emendas/emc/emc53.htm>. Acesso em: 29 mar. 2010.

Lei n. 11.494 de 20 de junho de 2007. Regulamenta o Fundo de Manutenção e Desenvolvimento da Educação Básica e de Valorização dos Profissionais da Educação FUNDEB, de que trata o art. 60 do Ato das Disposições Constitucionais Transitórias; e dá outras providências. Disponível em:

<http://www.planalto.gov.br/ccivil_03/_Ato20072010/2007/Lei/L11738.htm>. Acesso em: 29 mar. 2010.

Lei n. 11.738, de 16 de julho de 2008a. Regulamenta a alínea "e" do inciso III do caput do art. 60 do Ato das Disposições Constitucionais Transitórias, para instituir o piso salarial profissional nacional para os profissionais do magistério público da educação básica. Disponível em: <http://planalto.gov.br/ccivil_03/_Ato2007-

2010/2008/Lei/L11738.htm>. Acesso em: 29 mar. 2010.

. Supremo Tribunal Federal. Petição Inicial. Ação Direta de Inconstitucionalidade, 28/10/2008, 2008b. Disponível em:

$<$ www.stf.jus.br/portal/processo/verProcessoAndamento.asp?numero $=4167 \&$ classe $=$ ADI \& origem $=\mathrm{AP} \&$ recurso $=0 \&$ tipoJulgamento $=\mathrm{M}>$. Acesso em: 3 mar. 2010.

Supremo Tribunal Federal. Decisão Tribunal Pleno, 17 /12/2008c.

Acompanhamento Processual da ADI 4167 - Ação Direta de Inconstitucionalidade, 2008b. Disponível em:

$<$ www.stf.jus.br/portal/processo/verProcessoAndamento.asp?numero=4167\&classe=ADI \& origem $=\mathrm{AP} \&$ recurso $=0 \&$ tipoJulgamento $=\mathrm{M}>$. Acesso em: 3 mar. 2010.

CAMARGO, R. B. de, et al. Financiamento da educação e remuneração docente: um começo de conversa em tempos de piso salarial. In: Revista Brasileira de Política e Administração da Educação. Porto Alegre: v. 25 n. 2, mai-ago, p. 341-361, 2009. 
CEPAL, UNESCO. Educação e conhecimento: eixo da transformação produtiva com equidade. Brasília: IPEA/CEPAL/INEP, 1995.

\section{CONFEDERAÇÃO NACIONAL DOS TRABALHADORES EM EDUCAÇÃO.}

Disponível em:

$<$ http://www.cnte.org.br/index.php?option=com_content\&task=view\&id=1932\&Itemid=8

7>. Acesso em: 27 out. 2009.

Artigos: Uma aula de geografia sobre o Piso Salarial Profissional Nacional.

Disponível em:

$<$ http://www.cnte.org.br?index.php?option=com_content\&task=view\&id=1932\&Itemid=8 7>. Acesso em: 27 out. 2009.

. Noticias. Assessoria de Imprensa FETEMS-MS. Disponível em:

http://www.cnte.org.br/index.php?option=com_content\&task=view\&id=1932\&Itemid=87. Acesso em: 27 de out. 2009.

Posição da CNTE sobre o anúncio do projeto de lei de PSPN - piso salarial profissional nacional. Disponível em:

http://www.cnte.org.br/index.php?option=com_content\&task=view\&id=1932\&Itemid=87. Acesso em: 2 nov. 2009.

CRUZ, H. L. Condições de construção histórica do sindicalismo docente de educação básica. Tese (Doutorado em Sociologia). Universidade de Brasília, Brasília, 2008.

DAL ROSSO, S; LUCIO, M. de L. O Sindicalismo Tardio da Educação Básica no Brasil. Revista Universidade e Sociedade. Brasília-DF, ano XIV, n 33, junho: 115-125, 2004.

DAVIES, N. O Fundef e o orçamento da educação - desvendando a caixa preta.

Campinas, Autores Associados, 1999.

FERNANDES, M. D. E. O estado de Mato Grosso do Sul e os recursos vinculados constitucionalmente para a educação. In: SENNA, E. (Org.). Trabalho, educação e política pública. Campo Grande, UFMS, 2003.

HARVEY. D. O neoliberalismo - história e implicações. São Paulo, Edições Loyola, 2008.

JORNAL DO SENADO. Piso dos professores é lei, mas ainda não foi implantado 9/03/009. Disponível em: <

www.senado.gov.br/jornal/arquivos_jornal/avulsos/info319.htm>. Acesso em: 3 mar. 2010.

MONLEVADE, J. A. C. de. Valorização salarial dos professores. Tese (Doutorado em Educação). Universidade Estadual de Campinas, Campinas-SP, 2000.

MORAES, R. C. Reformas neoliberais e políticas públicas: hegemonia ideológica e redefinição das relações Estado-sociedade. In: Educação e Sociedade, v. 23, n. 80, p. 1324, Especial set. 2002.

NEVES, L. M. W. A sociedade civil como espaço estratégico de difusão da nova pedagogia da hegemonia. In: (Org.). A nova pedagogia da hegemonia estratégias do capital para educar o consenso. São Paulo, Xamã, 2005.

OLIVEIRA. F. de. Privatização do público, destituição da fala e anulação da política: o totalitarismo neoliberal. In: OLIVEIRA. F. de; PAOLI, M. C. (Orgs.). Os sentidos da democracia - políticas do dissenso e hegemonia global. Petrópolis, Vozes, Brasília, NEDIC, 1999. 
PERONI. V. M. V. Política educacional e papel do Estado no Brasil dos anos 1990. São Paulo, Xamã, 2003.

PINTO, J. M. de R. A política recente de fundos para o financiamento da educação e seus efeitos no pacto federativo. In: Educação \& Sociedade, v. 28, n. 100, p. 877-898, Especial out. 2007.

SMITH, A. A Riqueza das Nações: investigação sobre sua natureza e suas causas. São Paulo, Nova Cultural, $2^{a}$ edição, 1985.

Notas:

* Trabalho apresentado e debatido na 33 $3^{\text {a }}$ Reunião Anual da Associação Nacional de Pós-Graduação e Pesquisa em Educação (ANPEd) - "Educação no Brasil: o balanço de uma década", no Grupo de Trabalho Estado e Política Educacional, realizada em Caxambu, MG, de 17 a 21 de outubro de 2010. As alterações aqui apresentadas decorreram do debate no evento.

${ }^{1}$ A organização sindical dos docentes no Brasil surgiu tardiamente e é um fenômeno do século XX. A sindicalização dos professores, portanto, foi posterior ao movimento de organização dos trabalhadores brasileiros. Os trabalhadores docentes das principais cidades do país iniciaram o processo de criação de sindicatos durante os anos 1930, que foram consolidados na década seguinte (1940). Assim, por exemplo, em 1931 foi criado o Sindicato dos Trabalhadores do Ensino do Rio de Janeiro, de origem anarcosindicalista, que se opunha à política de Getúlio Vargas. Também no mesmo ano foi criado o Sindicato dos Professores do Ensino Secundário e Comercial do Distrito Federal, que nucleava professores de Ensino Secundário da rede privada. No estado de São Paulo, foi criada, em 1945, na cidade de São Carlos, a Associação dos Professores do Ensino Oficial do Estado de São Paulo (DAL ROSSO e LUCIO, 2004; CRUZ, 2008), e em 1938, no estado de Rio Grande do Sul, os professores de escolas particulares criaram o Sindicato do Ensino Primário, Secundário e de Artes do Rio Grande do Sul, que foi reconhecido em 1941. A luta sindical intensificou-se a partir de 1945, quando os professores das escolas públicas iniciaram o processo de organização nacional em defesa da escola pública e gratuita. Em 1960 criou-se a primeira Confederação dos Professores Primários do Brasil (CPPB). Em 1979, essa confederação incorporou os professores que atuavam no ensino médio e passou a denominar-se Confederação dos Professores do Brasil (CPB). Durante os anos de 1980, essa organização tornou-se a principal referência de sindicalização docente, mesmo com a proibição de sindicalização dos funcionários públicos e, em 1988, filiou-se à Central Única dos Trabalhadores (CUT). Em 1990 mudou o nome para Confederação Nacional dos Trabalhadores em Educação (CNTE), unificando várias Federações setoriais da educação do país.

${ }^{2}$ Artigo $2^{\circ}$ da Lei n. 9.424/1996.

${ }^{3}$ Artigo $4^{\circ}$ da Lei n. 9.424/1996.

Recebido em 04/11/2010

Aprovado em 23/12/2010 